\title{
EFEITOS DA EDUCAÇÃO NOS RENDIMENTOS DE HOMENS E MULHERES NO ESTADO DO PARANÁ: UMA ANÁLISE CONTRAFACTUAL
}

\author{
Adriana Pereira Pedra ${ }^{1}$ \\ Solange de Cassia Inforzato de Souza ${ }^{2}$ \\ Magno Rogério Gomes ${ }^{3}$
}

\begin{abstract}
RESUMO:
Este trabalho tem como objetivo estabelecer os efeitos da educação sobre os rendimentos dos trabalhadores ocupados, segundo o gênero, e sua evolução no Paraná, a partir dos microdados da PNAD 2005 e 2015. Para isso, foram efetuadas a mensuração dos determinantes salariais mincerianos e a tradicional decomposição de Oaxaca-Blinder. A decomposição contrafactual salarial constatou a elevação do hiato salarial entre homens e mulheres no Paraná, ao contrário da situação nacional, e a redução da discriminação de gênero e das diferenças salariais explicadas pelas características das trabalhadoras. A educação é a causa mais importante das diferenças salariais na perspectiva dos fatores produtivos e dos postos de trabalho, que favorece a mulher trabalhadora, muito embora esse legado positivo tenha sido reduzido no período.
\end{abstract}

Palavras-chave: Diferença salarial. Gênero. Educação. Paraná.

\section{EFFECTS OF EDUCATION ON THE INCOMES OF MEN AND WOMEN IN THE STATE OF PARANÁ: A COUNTERFACTUAL ANALYSIS}

\begin{abstract}
:
This work aims to establish the effects of education on the income of employed workers, according to gender, and its evolution in Paraná, from the microdata of PNAD 2005 and 2015. For this, the measurement of the mincerian wage determinants and the traditional decomposition of Oaxaca-Blinder were performed. The counterfactual wage decomposition found an increase in the wage gap between men and women, contrary to the national situation, and the reduction of gender discrimination and wage differences explained by the characteristics of the workers. Education is the most important cause of wage differences from the perspective of productive factors and jobs, which favors working women, although this positive legacy was reduced in the period.
\end{abstract}

Keywords: Wage Gap. Gender. Education. Paraná.

\footnotetext{
${ }^{1}$ Bacharel em Economia pela Universidade Estadual de Londrina, Paraná. Email: dri2307@hotmail.com

${ }^{2}$ Professora do Curso de Economia e do Programa de Mestrado em Economia Regional da Universidade Estadual de Londrina, Paraná. Email: solangecassia@uol.com.br Orcid: https://orcid.org/0000-0002-9806-2319

${ }^{3}$ Professor do Curso de Economia da Universidade Estadual de Londrina, Paraná. Email: magnorg86@gmail.com Orcid: https://orcid.org/0000-0002-7536-8710
} 


\section{EFECTOS DE LA EDUCACIÓN SOBRE LOS INGRESOS DE HOMBRES Y MUJERES EN EL ESTADO DE PARANÁ: UN ANÁLISIS CONTRAFACTUAL}

\section{RESUMEN:}

Este trabajo tiene como objetivo establecer los efectos de la educación en los ingresos de los trabajadores por cuenta ajena, según el género, y su evolución en Paraná, a partir de los microdatos de PNAD 2005 y 2015. Para ello, se realizó la medición de los determinantes salariales mincerios y la tradicional descomposición de Oaxaca-Blinder. La descomposición salarial contrafactual encontró un aumento de la brecha salarial entre hombres y mujeres, contrariamente a la situación nacional, y la reducción de la discriminación de género y las diferencias salariales explicadas por las características de los trabajadores. La educación es la causa más importante de diferencias salariales desde la perspectiva de factores productivos y empleos, lo que favorece a las mujeres trabajadoras, aunque este legado positivo se redujo en el período.

Palabras clave: Diferencia salarial. Género. Educación. Paraná.

\section{INTRODUÇÃO}

A literatura econômica sobre a educação no Brasil é extensa, principalmente no que diz respeito à sua relação com as desigualdades de salários dos indivíduos. Ademais, a participação econômica da mulher no mercado de trabalho tem mostrado padrões diferentes de remuneração entre os gêneros no país, como os detectados em Batista e Cacciamali (2009), Neri et al. (2009), Casari (2012), Branchi e Figueiredo (2013), Oliveira e Herek (2014), Pereira e Oliveira (2016).

De uma forma geral, a desigualdade de salários pode ser decorrente de dois fatores: a diferença dos atributos produtivos dos trabalhadores, educação e experiência, e o fato de trabalhadores com idêntica qualificação serem remunerados de forma distinta, seja porque são discriminados (tratamento diferenciado baseado em atributos não produtivos), seja porque o mercado de trabalho é segmentado - caso em que os postos de trabalho valorizam os atributos do trabalhador de forma diferente.

A possibilidade de agrupar os trabalhos empíricos sobre diferencial de salários entre os sexos em duas categorias distintas reflete o embate teórico existente na literatura sobre o tema. $\mathrm{Na}$ primeira categoria encontram-se os trabalhos que se baseiam na teoria do capital humano (Soares e Gonzaga (1997), Menezes-Filho (2001), Tavares e Menezes-Filho (2008), Suliano e Siqueira (2009), Fiuza-Moura, Souza e Maia (2014), Silva, França e Pinho Neto (2014) ) e, na segunda, estão aqueles que enfocam os modelos de segmentação, indicando a existência de barreiras ocupacionais segundo o gênero ou o papel da discriminação na explicação deste diferencial (Soares (2000), Chaves (2002), Maldaner (2004), Cacciamali e Hirata (2005), Moraes (2005), Nogueira e Marinho (2006), Maia et al. (2015), Mattei e Baço (2015) e Gomes (2016). 
No estado do Paraná, muito embora a renda per capita tenha sido inferior à renda per capita dos outros estados da região Sul, o nível de escolaridade dos ocupados maiores de 14 anos posiciona-se acima da média da Região sul do Brasil. As pesquisas sobre a medida econômica da educação para os trabalhadores homens e mulheres como fonte das diferenças salariais no Estado, todavia, são restritas. Diante disso, o principal objetivo deste artigo é dimensionar o papel da educação como causa das desigualdades de gênero dos trabalhadores ocupados no estado do Paraná, a partir os microdados da Pesquisa Nacional por Amostra de Domicílios - PNAD - de 2005 e 2015 .

Para tanto, este artigo encontra-se estruturado da seguinte maneira: além desta introdução, segue a seção 1, com o arcabouço empírico sobre as diferenças salariais no Brasil e no Paraná. Na segunda seção apresentam-se os procedimentos metodológicos adotados e na terceira interpreta os resultados obtidos na pesquisa. Por fim, a última seção apresenta as principais conclusões.

\section{As evidências empíricas sobre educação e desigualdades salariais de gênero}

Na perspectiva das diferenças salariais detectadas no Brasil, Cavalieri e Fernandes (1998), em seu estudo para as regiões metropolitanas brasileiras, apontaram que o diferencial de salários de gênero se mostrou sensível tanto a variações na idade como a variações nos anos de estudo. Araújo e Ribeiro (2000) concluíram que uma das maiores características do mercado de trabalho brasileiro é o diferencial salarial entre homens e mulheres, e os atributos produtivos, como a educação e a experiência, tiveram um papel secundário nesse processo, evidenciando a discriminação entre homens e mulheres.

Cacciamali e Hirata (2005), com dados para São Paulo e Bahia, confirmaram a discriminação racial e de gênero, em 2002, e a importância dos retornos da escolaridade. Nogueira e Marinho (2006) argumentaram que há discriminação contra mulheres no mercado de trabalho das regiões Nordeste e Sudeste, e que a diferença salarial de gênero contrária à mulher não se deve apenas a fatores educacionais, mas a outros fatores como a discriminação.

Para a Região Sul do Brasil, o trabalho de Jacinto (2005) mostrou que a discriminação de gênero ocorre no mercado de trabalho como um todo e também na indústria avícola da Região sul. A decomposição de Oaxaca demonstrou que 28,19\% do diferencial de salários existente devemse às diferenças nas características entre os homens e mulheres quanto ao nível de escolaridade, idade e tempo de emprego.

Berni, Barreto e Siqueira (2007) verificaram, no Nordeste do Brasil, no período de 1995 a 2005, que a variável mais determinante da desigualdade de rendimentos foi a educação. Também 


\section{FAZ CIÊNCIA, VOL. 23, N. 38, JUL/DEZ DE 2021 - P. 96 - 117}

para a Região Nordeste, Suliano e Siqueira (2009), a partir de suas principais forças econômicas (Bahia, Ceará e Pernambuco) entre 2001 e 2006, apontaram que o prêmio à escolaridade se manteve em patamares elevados, apesar da região nordestina ser caracterizada pela escassez educacional.

Catelan (2016), para o Sul do Brasil, em 2002 e 2013, constatou que houve um aumento no hiato salarial entre homens e mulheres devido, principalmente, à queda do ganho salarial feminino pelos atributos produtivos (educação e experiência). Pereira e Oliveira (2016) destacaram que no Rio Grande do Sul, no ano de 2010, a educação teve papel fundamental na determinação dos salários. Embora as mulheres possuíssem, em média, um ano a mais de escolaridade que os homens, tal magnitude não foi revertida nos seus rendimentos. Mattei e Baço (2015) argumentam que houve diferença salarial a favor dos homens na indústria de transformação de Santa Catarina, no ano de 2012 , sendo que $13,05 \%$ da diferença salarial de gênero no setor é explicada pelos atributos produtivos (educação e experiência).

No que se refere aos estudos para o estado do Paraná, Maldaner (2004), com base nos dados da PNAD e da RAIS de 2001, apontou que os salários femininos foram inferiores e constatou a discriminação contra as mulheres no mercado de trabalho formal do Paraná. A frequência feminina é superior à masculina nas faixas salariais menores, mesmo com o elevado grau de escolaridade em relação ao homem. Oliveira e Herek (2014) concluíram que, na microrregião de Paranavaí e o Paraná, com base nos dados do Censo Demográfico e da RAIS, houve desigualdade salarial entre gêneros, entre 2000 e 2010, que persistem mesmo com a existência de leis que atuam de forma a garantir a equidade de remuneração entre os gêneros.

Portanto, os estudos empíricos para o Brasil confirmaram a diferenciação salarial entre homens e mulheres, sendo perversa para a mulher, e evidenciaram, em grande parte, a existência da discriminação salarial de gênero e participação da educação nessa diferença. Diante da escassez de estudos sobre o tema no Paraná, a contribuição desta pesquisa é mensurar a contribuição da educação como causa da desigualdade salarial de gênero no Paraná, e sua evolução entre 2005 e 2015.

\section{ESTRATÉGIA METODOLÓGICA}

Este trabalho foi elaborado com a base de dados da Pesquisa Nacional por Amostra de Domicílios de 2005 e 2015 do IBGE. A PNAD foi interrompida em 2016, substituída pela PNAD contínua. Foram impostas algumas restrições, resultando em uma amostra de 167.549 indivíduos em 2005 e 153.566 em 2015 que se referem à população ocupada com idade igual ou superior a 
14 anos, remunerados no trabalho principal. O salários de 2005 foram reajustados para preços constantes de 2015 com base no IPCA acumulado.

Excluiu-se os indígenas, amarelos e os sem declaração de cor ou raça, os que se declararam como trabalhadores na produção para o próprio consumo, ou trabalhador na construção para o próprio uso ou trabalhador não-remunerado, os membros das forças armadas e auxiliares e as ocupações mal definidas. As variáveis estão explicitadas no Quadro 1.

\section{Quadro 1 - Descrição das variáveis explicativas utilizadas}

\begin{tabular}{|c|c|}
\hline Variável & Descrição da variável \\
\hline Educação & Anos de estudo que a pessoa possui na semana de referência. \\
\hline Exp & diferença entre a idade do indivíduo e a idade em que começou a trabalhar. \\
\hline exp2 & Variável experiência elevada ao quadrado. \\
\hline Formal & $\begin{array}{l}\text { variável binária igual a } 1 \text { para formal (empregados com carteira, funcionário público estatutário, } \\
\text { trabalhador doméstico com carteira, militar ou empregador) e igual a } 0 \text { para informal (outros } \\
\text { empregados sem carteira, empregados sem declaração de carteira, trabalhador doméstico sem carteira, } \\
\text { trabalhador doméstico sem declaração de carteira ou trabalhador por conta própria). }\end{array}$ \\
\hline Indtotal & $\begin{array}{l}\text { variável binária igual a } 1 \text { para pessoas que exercem atividades no setor industrial (outras atividades } \\
\text { industriais, indústria de transformação ou construção civil) e igual a } 0 \text { caso contrário. A variável de } \\
\text { referência é o setor agrícola. }\end{array}$ \\
\hline Comerc & $\begin{array}{l}\text { variável binária igual a } 1 \text { para pessoas que exercem atividades no setor de comércio (comércio e } \\
\text { reparação) e igual a } 0 \text { caso contrário. }\end{array}$ \\
\hline Servico & $\begin{array}{l}\text { variável binária igual a } 1 \text { para pessoas que exercem atividades no setor de serviços e igual a } 0 \text { caso } \\
\text { contrário. }\end{array}$ \\
\hline Dirigente & $\begin{array}{l}\text { variável binária igual a } 1 \text { para os trabalhadores que exercem a ocupação de dirigentes e igual a } 0 \text { caso } \\
\text { contrário. A variável de referência é o grupo ocupacional operacional (trabalhadores de serviços } \\
\text { administrativos, trabalhadores dos serviços, vendedores e prestadores de serviço do comércio, } \\
\text { trabalhadores agrícolas, trabalhadores da produção de bens e serviços e de reparação e manutenção). }\end{array}$ \\
\hline Pca & $\begin{array}{l}\text { variável binária igual a } 1 \text { para os indivíduos que são profissionais das ciências e das artes e igual a } 0 \\
\text { caso contrário. }\end{array}$ \\
\hline Técnico & variável binária igual a 1 para os indivíduos que são técnicos de nível médio e igual a 0 caso contrário. \\
\hline Urb & Variável binária igual a 1 para pessoas que vivem em áreas urbanas e igual a 0 para áreas rurais. \\
\hline Sul & $\begin{array}{l}\text { variável binária igual a } 1 \text { para pessoas que vivem na região Sul e igual a } 0 \text { caso contrário. A variável de } \\
\text { referência é a região Nordeste. }\end{array}$ \\
\hline Norte & variável binária igual a 1 para pessoas que vivem na região Norte e igual a 0 caso contrário. \\
\hline Sudeste & variável binária igual a 1 para pessoas que vivem na região Sudeste e igual a 0 caso contrário. \\
\hline Centrooeste & variável binária igual a 1 para pessoas que vivem na região Centro-Oeste e igual a 0 caso contrário \\
\hline DF & variável binária igual a 1 para pessoas que vivem no Distrito Federal e igual a 0 caso contrário \\
\hline Mulher & variável binária igual a 1 se o indivíduo for mulher, e 0 para homem. \\
\hline Branco & variável binária igual a 1 para indivíduos que se declaram de cor branca e igual a 0 caso preta ou parda. \\
\hline
\end{tabular}

Fonte: Elaboração própria. 


\section{Decomposição contrafactual dos salários}

Para este trabalho foram geradas equações mincerianas, para o Brasil e Paraná, homens e mulheres, para dois anos, 2005 e 2015, cujas formas funcionais são as seguintes:

Insalhora $=\beta_{0}+\beta_{1}$ educacao $+\beta_{2} \exp +\beta_{3} \exp 2+\beta_{4}$ mulher $+\beta_{5}$ branco $+\beta_{6}$ formal $+\beta_{7}$

indtotal $+\beta_{8}$ comerc $+\beta_{9}$ servico $+\beta_{10}$ dirigente $+\beta_{11}$ pca $+\beta_{12}$ tecnico $+\beta_{13}$ urb $+\beta_{14}$ sul $+\beta_{15}$ norte $+\beta_{16}$ sudeste $+\beta_{17}$ centrooeste $+\beta_{18} \mathrm{DF}+\mathrm{u}$

O método de Oaxaca-Blinder (1973) foi aplicado para decompor o diferencial de salário em duas partes: em geral, uma decorrente das diferenças de habilidade e outra devido à discriminação. O modelo de Oaxaca inicia-se com a seguinte equação minceriana:

$$
\operatorname{Ln}\left(\mathrm{W}_{\mathrm{i}}\right)=\mathrm{Z}_{\mathrm{i}}^{\prime} \beta+\mu_{\mathrm{i}} \quad \mathrm{i}=1, \ldots, \mathrm{n}
$$

Em que $\mathrm{W}_{\mathrm{i}}$ é o salário hora do trabalhador i; $\mathrm{Z}_{\mathrm{i}}$ é o vetor de características do trabalhador i; $\beta$ é o vetor de coeficientes de $Z_{i}^{\prime}$ e $\mu_{i}$ é o termo de erro. Utilizando a equação (2) para os grupos estudados a decomposição salarial é descrita em (3) conforme Oaxaca (1973).

$$
\operatorname{Ln}(\mathrm{G}+1)=\Delta Z^{\prime} \widehat{\beta}_{\mathrm{A}}+\mathrm{Z}_{\mathrm{B}}^{\prime} \Delta \widehat{\beta}
$$

Desse modo, o modelo elaborado por Oaxaca divide a equação (3) em duas parcelas, em que o termo $\Delta \mathrm{Z}^{\prime} \widehat{\beta}_{\mathrm{A}}$ mensura as diferenças de dotações entre os grupos A (homens) e B (mulheres), denominado de diferenças explicadas. Ele mostra quanto das diferenças salariais vem das diferenças nos atributos produtivos dos indivíduos. A segunda parcela, $Z_{B}^{\prime} \Delta \widehat{\beta}$, representa a diferença entre os coeficientes de A e B sobre as médias das características do grupo (B), as mulheres. O termo é denominado de diferenças não explicadas por que representa a parcela devida à discriminação de gênero.

\section{RESULTADOS E INTERPRETAÇÃO DA PESQUISA}

\section{Características da população ocupada no Paraná e as dimensões de gênero}

Os dados da Tabela 1 permitem afirmar que, em 2015, a maior parte da população paranaense é composta de indivíduos brancos e mulheres, reside em área urbana, são homens, mais velhos e chefes de família e trabalha no setor formal. Conforme esperado e com base na literatura publicada, as mulheres apresentaram uma média de anos de estudo maior que a dos homens, sendo 10,14 anos para elas em contraposição com 9,10 anos para eles, sendo o ganho das mulheres de $\mathrm{R} \$ 11,56$ e dos homens de $\mathrm{R} \$ 14,56$. 


\section{FAZ CIÊNCIA, VOL. 23, N. 38, JUL/DEZ DE 2021 - P. 96 - 117}

Tabela 1 - Perfil da população ocupada, segundo o gênero, no Paraná, 2005 - 2015

\begin{tabular}{|c|c|c|c|c|}
\hline \multirow[t]{2}{*}{ Variáveis } & \multicolumn{2}{|c|}{ Homem } & \multicolumn{2}{|c|}{ Mulher } \\
\hline & 2005 & 2015 & 2005 & 2015 \\
\hline Idade (média) & 37,43 & 39,37 & 35,38 & 38,37 \\
\hline Experiência (média) & 24,50 & 25,41 & 20,53 & 22,81 \\
\hline Anos de estudo (média) & 7,63 & 9,10 & 9,04 & 10,14 \\
\hline Salário mensal R \$ (média) & 1827,41 & 2361,27 & 1203,67 & 1649,08 \\
\hline $\begin{array}{l}\text { Horas trabalho/semana } \\
\text { (média) }\end{array}$ & 45,32 & 42,51 & 37,55 & 37,24 \\
\hline Salário hora $\mathrm{R} \$$ (média) & 10,30 & 14,56 & 8,71 & 11,56 \\
\hline Número de filhos (média) & - & - & 2,30 & 2,20 \\
\hline Região urbana (\%) & 82,72 & 86,36 & 91,75 & 91,29 \\
\hline Região rural (\%) & 17,28 & 13,64 & 8,25 & 8,71 \\
\hline Chefe de família (\%) & 72,11 & 61,09 & 25,96 & 33,81 \\
\hline Brancos (\%) & 72,69 & 67,03 & 75,92 & 72,16 \\
\hline Não Brancos (\%) & 27,31 & 32,97 & 24,08 & 27,84 \\
\hline Formal (\%) & 56,81 & 71,16 & 58,76 & 71,41 \\
\hline Informal $(\%)$ & 43,19 & 28,84 & 41,24 & 28,59 \\
\hline
\end{tabular}

Fonte: Elaboração própria, com base nos dados do IBGE/PNAD 2005-2015.

Comparando-se os dados de 2015 com os de 2005, houve aumento da participação relativa de indivíduos não brancos e mulheres, e da formalização no mercado de trabalho paranaense, assim como a redução de homens considerados chefes de família e do número médio de filhos. A experiência feminina aumentou mais do que a masculina e a média de anos de estudo aumentou para ambos os gêneros. Apesar do incremento nos salários para homens e mulheres, persitiu a discrepância entre homens e mulheres, favorável aos homens, no Estado, consistente com resultados das pesquisas de Maldaner(2004) e Oliveira e Herek (2014).

A análise do nível de escolaridade dos trabalhadores ocupados por gênero no Paraná deixa explícita que em 2015, a maior parte das mulheres e dos homens se concentrava na faixa de 9 a 11 anos de estudo (ensino fundamental completo) (

Gráfico 1). Cerca de $10 \%$ das mulheres e $7,78 \%$ dos homens se concentravam na faixa de estudo de 12 a 14 anos (ensino médio completo). Com 15 anos ou mais de estudo (ensino superior completo), o percentual feminino era de $22,10 \%$ em contraposição a $14,16 \%$ para os homens. Esses dados confirmam o fato das mulheres terem apresentado uma média de anos de estudo maior que a dos homens, com ascensão da escolaridade masculina no Paraná, comparandose com os dados de 2005. 


\section{FAZ CIÊNCIA, VOL. 23, N. 38, JUL/DEZ DE 2021 - P. 96 - 117}

Gráfico 1 - Participação (\%) dos trabalhadores ocupados, por gênero e anos de estudo no Paraná $2005-2015$

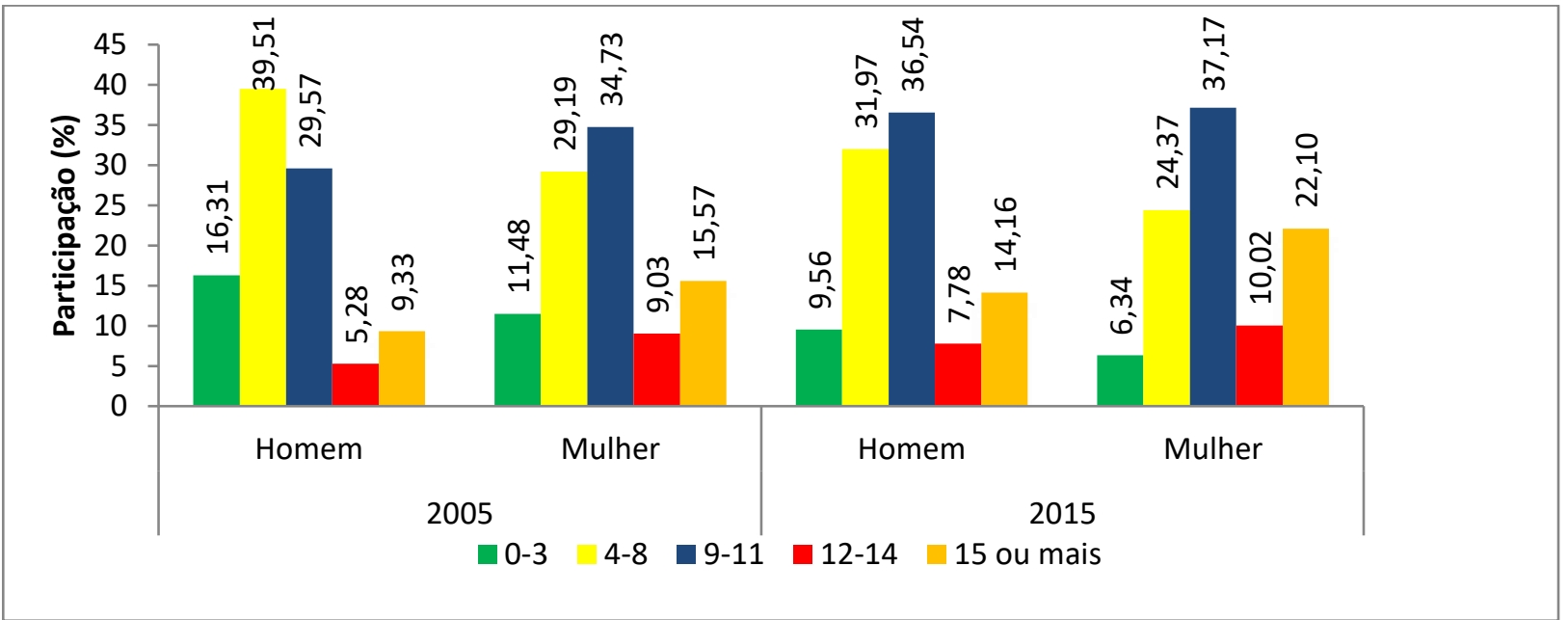

Fonte: Elaboração própria, com base nos dados do IBGE/PNAD 2005-2015.

O Gráfico 2 mostra que quanto maiores os anos de estudos, maiores são as diferenças salariais entre homens e mulheres. Entre os indivíduos de 12 a 14 anos de estudo, as mulheres ganhavam 67,23\% do salário médio dos homens, já na faixa de 15 anos ou mais este percentual era de $63,79 \%$. No período, tem-se um aumento do nível salarial para todas as faixas de estudo e para ambos os gêneros, porém persistem as diferenças entre os ganhos masculinos em detrimento dos femininos, com os mesmos níveis educacionais, maiores nas faixas de anos de estudo mais elevadas.

Gráfico 2 - Salário hora real médio $(\mathrm{R} \$$ ) dos trabalhadores ocupados, por gênero e anos de estudo no Paraná 2005 - 2015

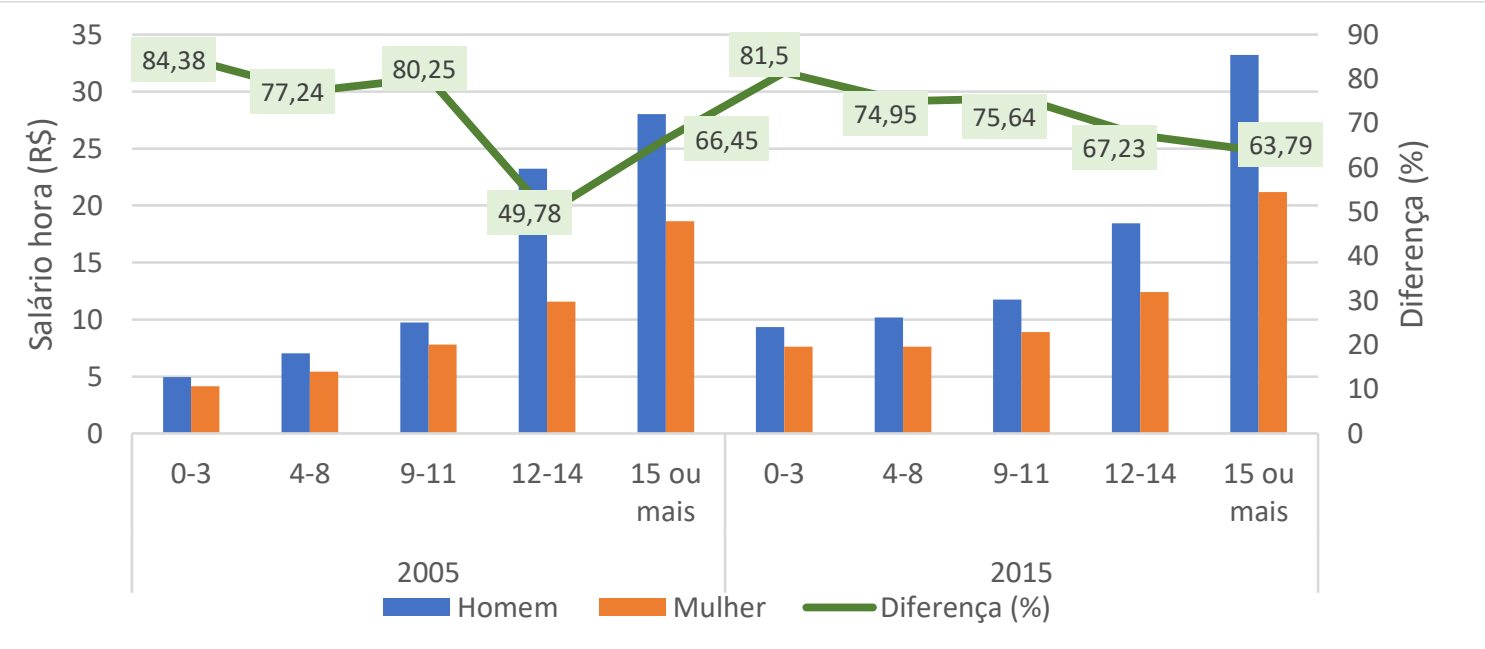

Fonte: Elaboração própria, com base nos dados do IBGE/PNAD 2005-2015. 


\section{FAZ CIÊNCIA, VOL. 23, N. 38, JUL/DEZ DE 2021 - P. 96 - 117}

Em seguida, o Gráfico 3 revela os níveis de escolaridade mais elveados em postos de trabalho relacionados aos dirigentes e profissionais das ciências e das artes. Para todos os cargos, os anos de estudo médio das mulheres eram maiores que dos homens, exceto entre os trabalhadores dos serviços, mantendo essa tendência no período.

Gráfico 3 - Anos de estudo médio dos trabalhadores ocupados, por ocupação e gênero no Paraná $2005-2015$

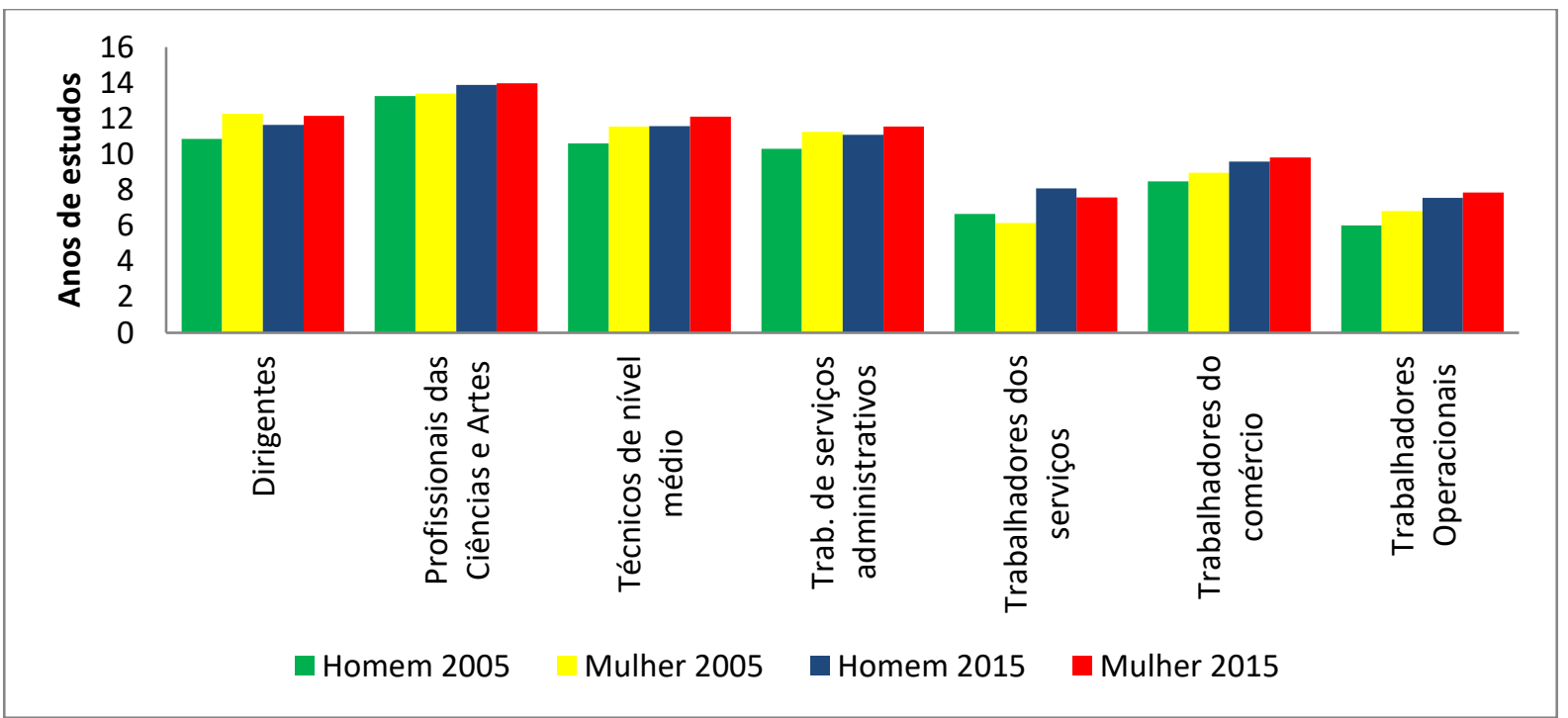

Fonte: Elaboração própria, com base nos dados do IBGE/PNAD 2005-2015

No geral, as ocupações que exigem mais escolaridade ou qualificações apresentaram salários horas médios mais elevados e as ocupações que requerem baixa qualificação ou baixo nível educacional, como os trabalhadores operacionais, mostraram baixos níveis de salários horas (Gráfico 4). Houve discrepância salarial a favor dos homens em todos os níveis ocupacionais, porém esta se destacou entre os profissionais das ciências e das artes e os técnicos de nível médio; no primeiro caso, as mulheres ganhavam $61,22 \%$ do salário dos homens e no segundo caso elas ganhavam $71,81 \%$ do salário deles.

A constatação de que as mulheres, em média, apresentavam mais anos de estudo que os homens em quase todos os grupos ocupacionais e visto que houve discrepância salarial a favor dos homens em todos os cargos, revela a necessidade de associar a teoria do capital humano a outras teorias (segmentação ou discriminação) para explicar as desigualdades salariais de gênero. 


\section{FAZ CIÊNCIA, VOL. 23, N. 38, JUL/DEZ DE 2021 - P. 96 - 117}

Gráfico 4 - Salário hora real médio $(\mathrm{R}$ \$) dos trabalhadores ocupados, por gênero e ocupação no Paraná $2005-2015$

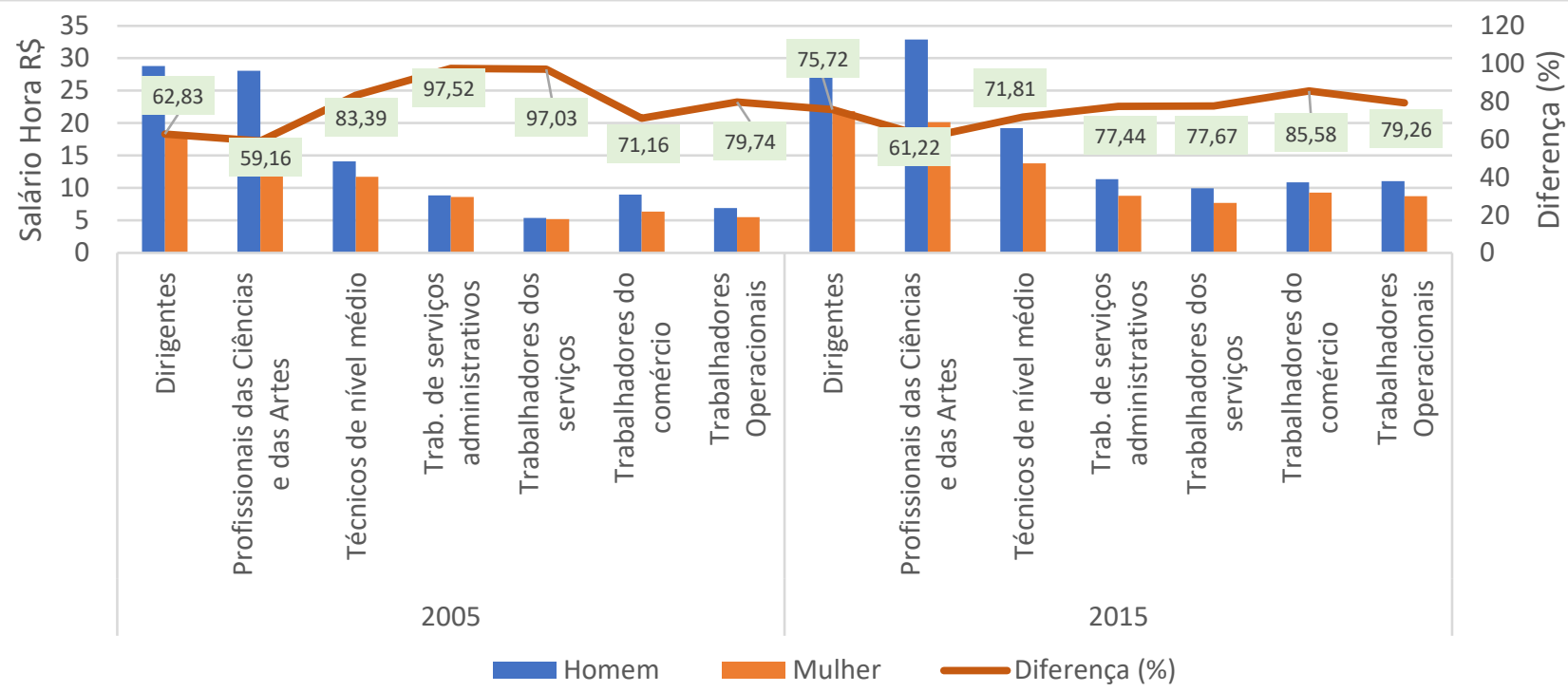

Fonte: Elaboração própria, com base nos dados do IBGE/PNAD 2005-2015.

Em relação aos anos de estudo médios dos trabalhadores ocupados, por setor econômico e gênero no estado, para o ano de 2015, a média feminina foi superior à masculina em todos os setores econômicos com exceção da indústria de construção civil. A maior diferença de escolaridade entre gêneros se deu na indústria de transformação em que a média de anos de estudo das mulheres era de 10,44 em contraposição a 7,18 anos dos homens (Gráfico 5).

Gráfico 5 - Anos de estudo médio dos trabalhadores ocupados, por setor econômico e gênero no Paraná $2005-2015$

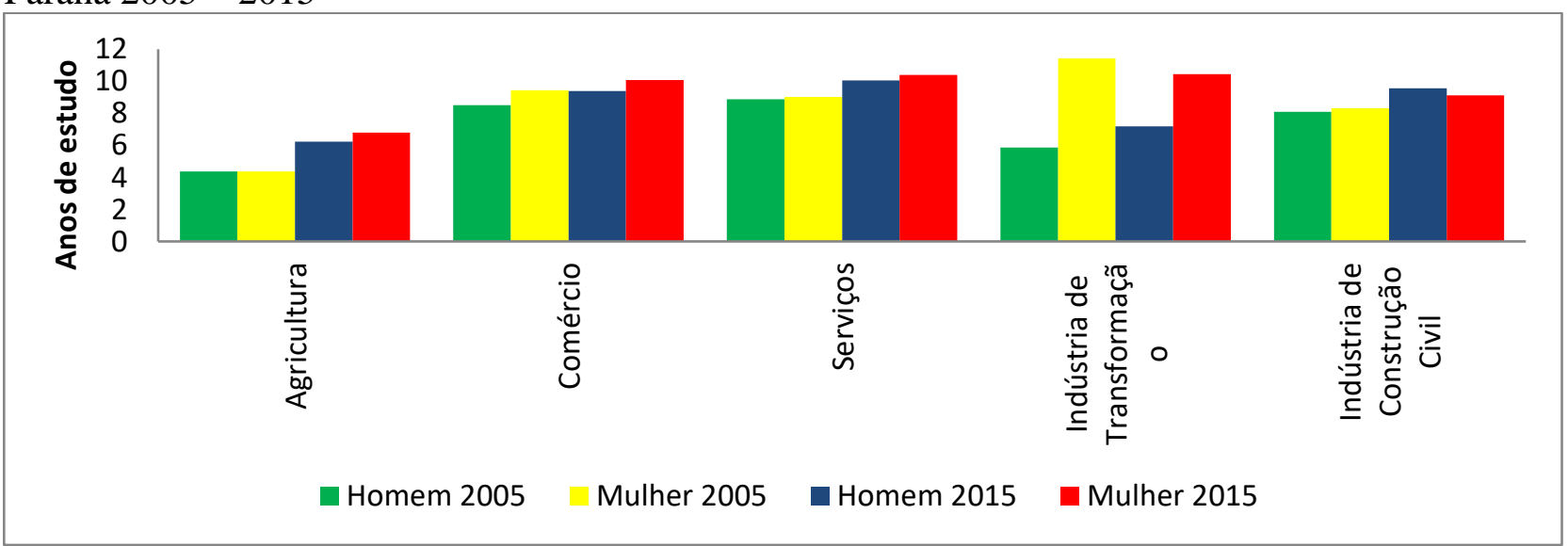

Fonte: Elaboração própria, com base nos dados do IBGE/PNAD 2005-2015. 


\section{FAZ CIÊNCIA, VOL. 23, N. 38, JUL/DEZ DE 2021 - P. 96 - 117}

Apesar das mulheres terem estudado mais que os homens na maioria dos setores, houve discrepância salarial a favor deles na agricultura, comércio, serviços e na construção civil. Porém, na indústria de transformação, mulheres auferiram ganhos superiores aos homens (Erro! Autoreferência de indicador não válida.). Essa mesma tendência ocorreu entre 2005 e 2015: a média feminina de escolaridade superou a masculina no comércio, serviços, indústria de transformação e de construção civil, sendo que nesta última as mulheres possuíam, em média, 8,32 anos de estudo em contraposição a 8,10 de homens. A indústria de transformação continuou apresentando a maior diferença de escolaridade entre gêneros, mas não revelou discrepância salarial a favor dos homens, ao contrário dos demais setores econômicos.

Gráfico 6 - Salário hora médio $(\mathrm{R} \$$ ) dos trabalhadores ocupados, por setor econômico e gênero no Paraná 2005 - 2015

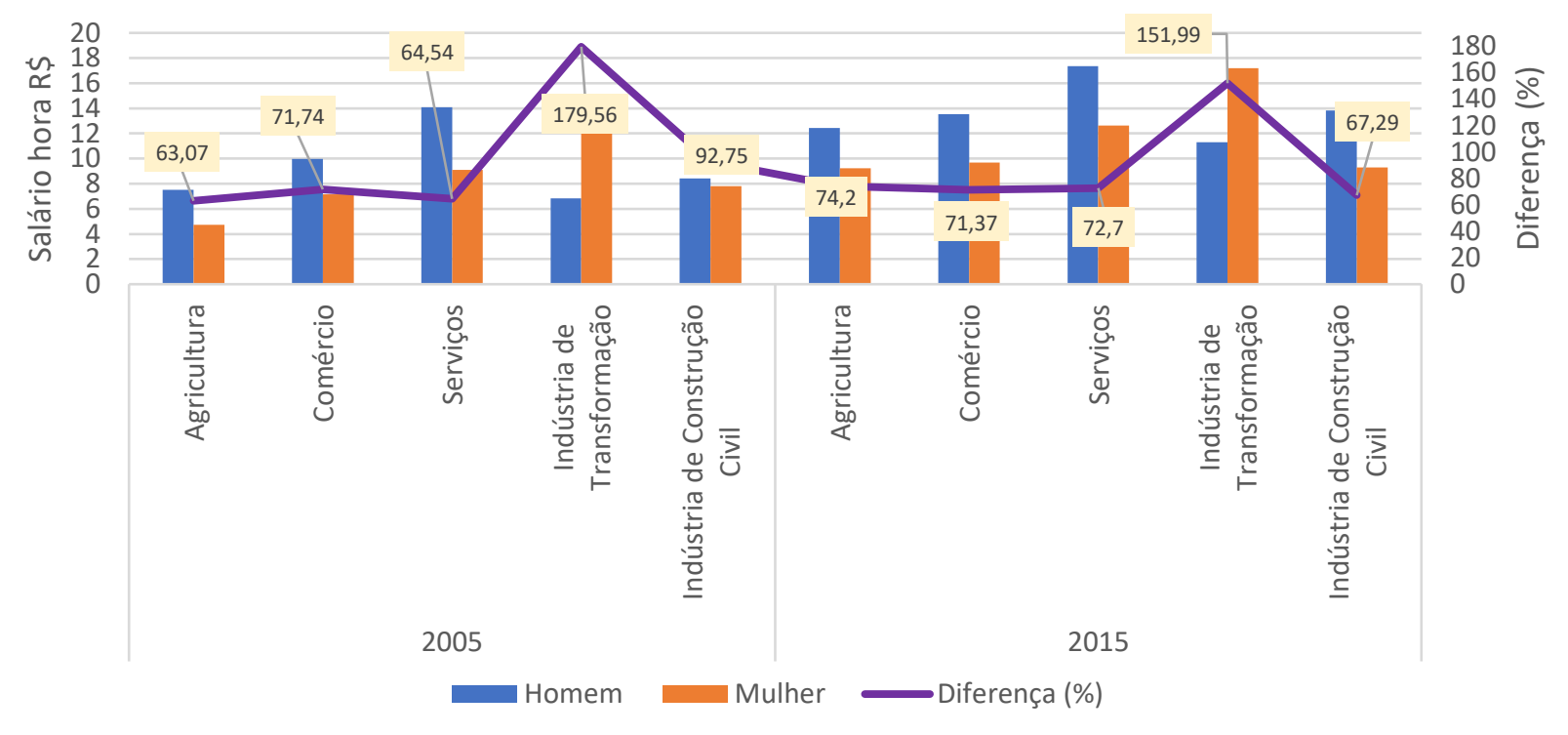

Fonte: Elaboração própria, com base nos dados do IBGE/PNAD 2005-2015.

Apesar da elevação do nível salarial para ambos os gêneros, o setor de serviços pagou o maior salário médio para os homens e a indústria de transformação pagou o salário médio mais elevado para as mulheres. De modo geral, a discrepância salarial se manteve a favor dos homens no Paraná na maioria dos setores econômicos nos dois anos estudados: em 2005, as mulheres recebiam 63,07\% dos salários masculinos na agricultura; em 2015, as mulheres ganhavam 67,29\% dos salários dos homens na construção civil, por exemplo. Diante disso, esta investigação quer detalhamento sobre as causas das diferenças salariais entre os gêneros no Estado do Paraná e, especialmente, o efeito da educação nessas desigualdades de rendimentos. 


\section{Decomposição salarial e o impacto da educação das desigualdades de gênero no Paraná}

Nesta seção, inicialmente, estimam-se as equações salariais do Brasil, do Paraná e para homens e mulheres do Paraná, para os anos de 2005 e 2015. A Tabela 2 apresenta os coeficientes das equações de determinação dos salários no Brasil e no Paraná, considerando a população ocupada maior ou igual a 14 anos de idade.

Tabela 2 - Equações salariais para o Brasil e o Paraná, 2005 e 2015

\begin{tabular}{|c|c|c|c|c|c|c|c|c|}
\hline \multirow{3}{*}{ Variáveis } & \multirow{2}{*}{\multicolumn{2}{|c|}{ Brasil }} & \multirow{2}{*}{\multicolumn{2}{|c|}{ Paraná }} & \multicolumn{4}{|c|}{ Paraná } \\
\hline & & & & & \multicolumn{2}{|c|}{ Mulher } & \multicolumn{2}{|c|}{ Homem } \\
\hline & 2005 & 2015 & 2005 & 2015 & 2005 & 2015 & 2005 & 2015 \\
\hline Educação & $0,0748^{*}$ & $0,0555^{*}$ & $0,0798 *$ & $0,0501^{*}$ & $0,0723^{*}$ & $0,0488 *$ & $0,0847^{*}$ & $0,0506^{*}$ \\
\hline Experiência & $0,0302 *$ & $0,0223 *$ & $0,0318 *$ & $0,0255^{*}$ & $0,0272 *$ & $0,0242 *$ & $0,0358 *$ & $0,0274 *$ \\
\hline Experiência $^{2}$ & $-0,0003^{*}$ & $-0,0002 *$ & $-0,0003 *$ & $-0,0003^{*}$ & $-0,0003 *$ & $-0,0003 *$ & $-0,0004 *$ & $-0,0003 *$ \\
\hline Mulher & $-0,2403^{*}$ & $-0,2359 *$ & $-0,2380 *$ & $-0,2408 *$ & - & - & - & - \\
\hline Branco & $0,1335^{*}$ & $0,1137 *$ & $0,0993 *$ & $0,1024 *$ & $0,1003^{*}$ & $0,1200 *$ & $0,0950^{*}$ & $0,0896^{*}$ \\
\hline Formal & $0,3179 *$ & $0,2242 *$ & $0,2009 *$ & $0,1430 *$ & $0,2222 *$ & $0,1378 *$ & $0,1898 *$ & $0,1476^{*}$ \\
\hline Indústria & $0,1769^{*}$ & $0,2242 *$ & $0,1837 *$ & $0,1185^{*}$ & $0,1903^{*}$ & 0,0306 & $0,1909^{*}$ & $0,1426^{*}$ \\
\hline Comércio & $0,1378^{*}$ & $0,1263 *$ & $0,1677 *$ & $0,0838 *$ & $0,1660^{*}$ & 0,0309 & $0,1693 *$ & $0,0922 * *$ \\
\hline Serviços & $0,2252 *$ & $0,2870 *$ & $0,2138 *$ & $0,2119 *$ & $0,2134 *$ & $0,1611 * *$ & $0,2114 *$ & $0,2090 *$ \\
\hline Dirigentes & $1,0601^{*}$ & $0,7803 *$ & $1,0306^{*}$ & $0,7277 *$ & $0,9635^{*}$ & $0,7198^{*}$ & $1,0739 *$ & $0,7343 *$ \\
\hline PCAs & $0,9943^{*}$ & $0,8565 *$ & $0,7820 *$ & $0,7250 *$ & $0,6922 *$ & $0,6593 *$ & $1,0163 *$ & $0,8550 *$ \\
\hline Técnicos & $0,4786^{*}$ & $0,3435 *$ & $0,3262 *$ & $0,3282 *$ & $0,2783^{*}$ & $0,2676^{*}$ & $0,3713 *$ & $0,3760 *$ \\
\hline Urbano & $0,1153^{*}$ & $0,1780 *$ & $0,1209 *$ & $0,1072 *$ & $0,1743^{*}$ & $0,0713 * *$ & $0,0897 *$ & $0,1249 *$ \\
\hline Sul & $0,3960^{*}$ & $0,3874 *$ & - & - & - & - & - & - \\
\hline Norte & $0,3895^{*}$ & $0,2343^{*}$ & - & - & - & - & - & - \\
\hline Sudeste & $0,4060 *$ & $0,3872 *$ & - & - & - & - & - & - \\
\hline Centro-Oeste & $0,4101^{*}$ & $0,4228 *$ & - & - & - & - & - & - \\
\hline Distrito Federal & $0,8591 *$ & $0,9523 *$ & - & - & - & - & - & - \\
\hline Constante & $-0,1033^{*}$ & $0,5192 *$ & $0,2398 *$ & $1,6650 *$ & 0,0314 & $1,3185^{*}$ & $0,1542 *$ & $1,4856^{*}$ \\
\hline
\end{tabular}

Fonte: Elaboração própria, com base nos dados do IBGE/PNAD 2005-2015.

Notas: (*) significância a 5\%. Os valores apresentados acima são o antilogaritmo para apresentar o efeito composto ou real. Utilizou-se $\left(\mathrm{e}^{(\mathrm{c})}-1\right) \times 100$. Foram aplicados testes de multicolinearidade, omissão de variáveis e heterocedasticidade. Para minimizar o problema de heterocedasticidade, utilizou-se o procedimento de erros robusto de White.

Para o Paraná, em 2015, as características produtivas como educação e experiência impactaram positivamente os salários horas dos trabalhadores e, assim como observado no Brasil como um todo, o retorno percentual de um ano a mais de estudo $(5,01 \%)$ foi superior ao retorno 
percentual de um ano adicional de experiência (2,55\%). O sinal negativo da variável experiência ${ }^{2}$ indica que o ganho percentual apresenta rendimentos decrescentes, conforme esperado pela teoria do capital humano.

Apesar da influência do capital humano nos rendimentos dos ocupados no Paraná, outros fatores são importantes conforme sustenta a teoria econômica da discriminação. Assim como no caso brasileiro, as mulheres auferiram salários horas inferiores em aproximadamente $24 \% \mathrm{em}$ relação aos dos homens. Os brancos receberam $10,24 \%$ a mais que os não brancos no estado, porém, no Brasil, este percentual foi superior (11,37\%).

Por outro lado, a tese da segmentação do mercado de trabalho aponta características que devem ser observadas. Os indivíduos do segmento formal ganhavam 14,30\% a mais que os trabalhadores do segmento informal (ganho percentual inferior ao nacional). O setor que apresentou maiores ganhos relativos sobre os salários horas da agricultura foi o de serviços, seguido pela indústria e comércio, sendo tal comportamento observado tanto em nível estadual como nacional. Para o Paraná esses ganhos percentuais eram de 21,19\%, 11,85\% e 8,38\%, respectivamente. Os dirigentes foram os que receberam maiores retornos percentuais em relação aos trabalhadores operacionais, seguidos dos PCAs e dos técnicos de nível médio; estes ganhos foram de $72,77 \%, 72,50 \%$ e 32,82\%, respectivamente. Na análise nacional os rendimentos dos PCAs em relação aos operacionais foram superiores aos ganhos dos dirigentes em relação ao mesmo cargo em 2015.

No que se refere à situação censitária, morar em área urbana garantia um impacto positivo de 10,72\% nos salários horas dos indivíduos em relação aos moradores de área rural em 2015. Este ganho percentual foi inferior ao âmbito nacional no mesmo ano.

Comparando os dados do Paraná de 2015 com os de 2005, no que se refere às características produtivas, por exemplo, houve redução dos retornos percentuais de um ano a mais de estudo e de experiência, contudo, o retorno de um ano adicional de educação foi superior a um ano adicional de experiência. O mesmo comportamento pode ser notado para o Brasil, mas a queda do retorno da escolaridade no Paraná foi maior que no Brasil como um todo.

No que se refere às características não produtivas como gênero e cor da pele, houve redução do retorno percentual das mulheres em relação aos homens e aumento do ganho percentual dos indivíduos brancos relativamente aos não brancos. Em âmbito nacional, houve redução deste último percentual de 13,35\% para 11,37\%. 
Em relação às características do mercado de trabalho, houve redução do ganho percentual dos trabalhadores do segmento formal em relação aos do segmento informal, e se mantiveram inferiores ao âmbito nacional nos dois anos analisados. A tendência dos setores econômicos se manteve inalterada uma vez que se observa o mesmo processo ocorrer no ano de 2005: embora os ganhos relativos tenham sofrido redução no caso paranaense, o setor que apresentou maiores ganhos relativos foi o de serviços, seguido pela indústria e comércio, assim como na análise nacional.

Embora os ganhos relativos tenham apresentado redução para os dirigentes e PCAs e aumento para os técnicos de nível médio, o cargo de dirigente apresentou maior ganho percentual em relação aos trabalhadores operacionais, seguido pelos PCAs e técnicos de nível médio nos dois anos analisados. No que se refere à situação censitária, houve redução do impacto positivo de morar em área urbana em relação aos moradores de área rural, todavia, em âmbito nacional, este ganho percentual aumentou.

Com o propósito de relacionar as características separadamente de homens e mulheres com seus rendimentos, a população do Paraná dividida por gênero e as respectivas equações de salários horas para mulheres e homens nos anos de 2005 e 2015.

Quanto às características produtivas, destaca-se novamente o retorno positivo de um ano a mais de estudo em 2015: o impacto sobre os salários horas masculinos foi de 5,06\% e de 4,88\% sobre os salários femininos. A relevância da escolaridade como variável determinante dos salários de homens e mulheres é mencionada na literatura econômica, seja para o Brasil, seja para os estados federativos, indicados por Cacciamali e Hirata (2005), Suliano e Siqueira (2009) e Pereira e Oliveira (2016), ou para macrorregiões do país, como em Berni, Barreto e Siqueira (2007). Além disso, um ano adicional de experiência também apresentou retorno positivo sobre os salários: $2,74 \%$ no caso dos homens e $2,42 \%$ no caso das mulheres. Os respectivos retornos no caso dos homens foram superiores aos das mulheres. Em relação à cor da pele, característica não produtiva, a tendência foi de indivíduos brancos garantirem um acréscimo sobre os salários horas dos não brancos, mais acentuado no caso das mulheres, isto é, as mulheres brancas ganhavam $12 \%$ a mais que as mulheres negras e os homens brancos recebiam $8,96 \%$ a mais que os homens não brancos.

No que tange às características do mercado de trabalho paranaense, para as mulheres, $o$ acréscimo de trabalhar no segmento formal equivalia a um ganho de 13,78\% sobre os salários, enquanto para os homens este percentual foi superior $(14,76 \%)$. O setor de serviços apresentou os 


\section{FAZ CIÊNCIA, VOL. 23, N. 38, JUL/DEZ DE 2021 - P. 96 - 117}

maiores retornos comparativamente à agricultura, seguido pela indústria e comércio, para ambos os gêneros. Os dirigentes e profissionais das ciências e das artes apresentaram os maiores retornos em relação aos trabalhadores operacionais (omitido), com vantagens para os homens. Os retornos sobre o salário hora de mulheres residentes em áreas urbanas em comparação com as moradoras de áreas não urbanas foi inferior aos ganhos dos homens, sendo estes percentuais iguais a 7,13\% e $12,49 \%$, respectivamente.

Quando se compara os dados de 2015 com os de 2005, tem-se o seguinte. No caso das características produtivas, a educação e a experiência proporcionaram retornos maiores para os homens do que para as mulheres, porém estes retornos sofreram queda. $\mathrm{O}$ acréscimo que indivíduos brancos garantem sobre o salário hora em relação aos não brancos foi mais pronunciado para as mulheres do que para os homens nos dois anos analisados; no caso das mulheres este retorno percentual apresentou elevação, e para a população masculina mostrou redução.

No que tange às características do mercado de trabalho, enfatiza-se que o retorno percentual sobre o salário hora do segmento formal em relação ao informal que era mais acentuado para as mulheres, passou a ser mais acentuado para os homens. Quanto aos setores econômicos, houve redução de intensidade no impacto salarial quando comparados ao setor agrícola. De acordo com as ocupações, os dirigentes e profissionais das ciências e das artes também apresentaram os retornos mais elevados quando comparados aos trabalhadores operacionais, com claras vantagens para os homens. O acréscimo salarial que moradores de áreas urbanas garantem em relação aos residentes em áreas não urbanas que era maior no caso feminino passou a ser maior no caso masculino.

A partir das equações salariais, desenvolveram-se as decomposições salariais entre homens e mulheres para os anos de 2005 e 2015 (Tabela 3). No Brasil, em 2015, a diferença total entre os salários masculinos e femininos era de $6,69 \%$, com duas possíveis explicações. A teoria da discriminação de gênero no mercado de trabalho enuncia que mantidos todos os fatores constantes (educação, experiência, cor da pele, setor econômico, grupo ocupacional e área censitária), se ainda assim persistirem as diferenças salariais, há discriminação decorrente do grupo vulnerável (mulheres). Os dados confirmam a ocorrência deste fenômeno no Brasil, uma vez que num cenário sem discriminação o salário das mulheres deveria aumentar 29,16\%. 
Tabela 3 - Decomposição salarial para homens e mulheres no Brasil e Paraná para 2005 e 2015

\begin{tabular}{|c|c|c|c|c|c|c|c|c|}
\hline \multirow{3}{*}{ Grupos } & \multicolumn{4}{|c|}{ Coeficientes do salário } & \multicolumn{4}{|c|}{ Coeficientes na forma exponencial } \\
\hline & \multicolumn{2}{|c|}{ Brasil } & \multicolumn{2}{|c|}{ Paraná } & \multicolumn{2}{|c|}{ Brasil } & \multicolumn{2}{|c|}{ Paraná } \\
\hline & 2005 & 2015 & 2005 & 2015 & 2005 & 2015 & 2005 & 2015 \\
\hline Homens & 1,6037 & 2,0083 & 1,7831 & 2,2132 & 4,9717 & 7,4507 & 5,9485 & 9,1458 \\
\hline Mulheres & 1,5279 & 1,9434 & 1,6689 & 2,0835 & 4,6085 & 6,9830 & 5,3063 & 8,0331 \\
\hline Diferenças & \multicolumn{4}{|c|}{ Coeficientes } & \multicolumn{4}{|c|}{ Impacto percentual no salário } \\
\hline Explicada Total & $-0,1971$ & $-0,1910$ & $-0,1649$ & $-0,1461$ & $-17,90 *$ & $-17,40 *$ & $-15,21 *$ & $-13,60 *$ \\
\hline Educação & $-0,1213$ & $-0,0874$ & $-0,1218$ & $-0,0584$ & $-11,43^{*}$ & $-8,38 *$ & $-11,48^{*}$ & $-5,68 *$ \\
\hline Experiência & 0,0996 & 0,0520 & 0,1436 & 0,0653 & $10,47^{*}$ & $5,34 *$ & $15,45^{*}$ & $6,75^{*}$ \\
\hline Branco & $-0,0046$ & $-0,0046$ & $-0,0029$ & $-0,0046$ & $-0,47^{*}$ & $-0,47 *$ & $-0,30^{*}$ & $-0,47 *$ \\
\hline Mercado Formal & $-0,0037$ & $-0,0040$ & $-0,0038$ & $-0,0004$ & $-0,38 *$ & $-0,41 *$ & $-0,39 * *$ & $-0,05$ \\
\hline Setor & $-0,0434$ & $-0,0257$ & $-0,0339$ & $-0,0306$ & $-4,26 *$ & $-2,55^{*}$ & $-3,34 *$ & $-3,03 *$ \\
\hline Ocupação & $-0,0476$ & $-0,0667$ & $-0,0566$ & $-0,0612$ & $-4,66^{*}$ & $-6,47^{*}$ & $-5,51 *$ & $-5,94 *$ \\
\hline Região Urbana & $-0,0083$ & $-0,0119$ & $-0,0085$ & $-0,0066$ & $-0,84^{*}$ & $-1,19^{*}$ & $-0,86^{*}$ & $-0,67 *$ \\
\hline Região & $-0,0087$ & $-0,0087$ & -- & -- & $-0,87 *$ & $-0,88$ & -- & - \\
\hline Discriminação de gênero & 0,2730 & 0,2558 & 0,2791 & 0,2758 & $31,39 *$ & $29,16 *$ & $32,20 *$ & $31,76^{*}$ \\
\hline Diferença total & 0,0758 & 0,0648 & $\mathbf{0 , 1 1 4 2}$ & 0,1297 & $7,88 *$ & $6,69 *$ & $12,10 *$ & $13,85^{*}$ \\
\hline
\end{tabular}

Fonte: Elaboração própria com base nos dados da PNAD 2005 e 2015.

Nota: (*) significância a $5 \%$.

Por outro lado, a teoria do capital humano defende que à medida que o nível educacional de um indivíduo cresce, aumenta-se a habilidade cognitiva e a produtividade da mão de obra, permitindo com que o indivíduo receba maiores rendas do trabalho. Os dados de 2015 mostram que se a educação feminina fosse igualada à masculina no país, haveria uma redução de 8,38\% nos salários das mulheres, isso significa que a educação amorteceu o impacto desfavorável nos salários das mulheres. Se as mulheres tivessem a mesma experiência que os homens, seus salários aumentariam em 5,34\%, ou seja, a experiência contribuiu para o aumento da diferença salarial de gênero. Se agregar a educação e a experiência a outras características do mercado de trabalho, a parcela da diferença explicada pelas características produtivas resulta em $-17,40 \%$, sendo que a educação é a que mais impacta favoravelmente a redução da diferença salarial entre homens e mulheres.

Entre 2015 e 2005, a diferença total entre os salários masculinos e femininos reduziu de $7,88 \%$ para $6,69 \%$, que pode ser explicado, em parte, pela redução da discriminação de gênero de 
$31,39 \%$ para $29,16 \%$. No que se refere à educação, ela continuou contribuindo para reduzir a diferença salarial de gênero, no entanto, essa contribuição para a redução foi menor se comparado com 2005. A experiência contribuiu menos para o aumento das diferenças de salários entre homens e mulheres.

Para a análise estadual da população ocupada, os dados são os de que, em 2015, a diferença entre os salários masculinos e femininos era de 13,85\% (maior que no Brasil), sendo que este diferencial pode ser explicado pela discriminação e/ou pelos fatores relacionados aos fatores produtivos e postos de trabalho. Os dados confirmam a ocorrência da discriminação salarial de gênero no Paraná, uma vez que num cenário sem discriminação o salário das mulheres deveria aumentar $31,76 \%$ (percentual maior que no Brasil).

Por outro lado, a educação também pode afetar as desigualdades salariais de gênero no Paraná, porque segundo a teoria do capital humano, aumenta a habilidade cognitiva dos indivíduos e consequentemente, sua produtividade, possibilitando assim, maiores rendimentos. Os dados de 2015 mostram que se a educação feminina fosse igualada à masculina no Paraná, haveria uma redução de 5,68\% nos salários das mulheres, isso indica que a educação impacta favoravelmente os salários das mulheres, porém o impacto da educação foi menor no Paraná do que no Brasil como um todo. Se as mulheres tivessem a mesma experiência que os homens, seus salários aumentariam em $6,75 \%$, ou seja, a experiência tem efeito desfavorável para as mulheres. Se agregar a educação e a experiência a outras características do mercado de trabalho, a parcela da diferença explicada por esses fatores resulta em $-13,60 \%$.

A comparação realizada pelos dois anos indica três observações necessárias: (i) a diferença entre os salários masculinos e femininos aumentou de 12,10\% para 13,85\%, que segue na contramão dos dados para o Brasil; (ii) a discriminação salarial de gênero reduziu de 32,30\% para $31,76 \%$, o que constitui um fato relevante, que segue a realidade do país. No que se refere ao papel da educação, (iii) é uma fonte importante para a redução das diferenças salariais de gênero, mas há o impacto menor para os salários femininos no ano mais recente, na ordem de 5,8p.p, pois a ascensão da escolaridade dos homens ocupados foi percentualmente maior em relação às mulheres, conforme exposta na seção 3.1. Este fenômeno de perda de força para amortecer as diferenças salariais por parte da educação não é exclusivamente paranaense, e sim brasileiro, mas no Paraná este fato foi mais intenso que no Brasil como um todo. Por fim, a experiência, que tem consequências adversas para os salários das mulheres, contribuiu menos para o aumento das 


\section{FAZ CIÊNCIA, VOL. 23, N. 38, JUL/DEZ DE 2021 - P. 96 - 117}

diferenças de salários entre homens e mulheres. Uma síntese de todos os resultados da pesquisa para o Brasil e o estado do Paraná é apresentada na Tabela 4.

Tabela 4 - Síntese (\%) da Decomposição de Oaxaca-Blinder entre homens e mulheres no Brasil e no Paraná, para 2005 e 2015

Impacto nos salários (\%)

\begin{tabular}{|c|c|c|c|c|}
\hline \multirow{2}{*}{ Parte do diferencial } & \multicolumn{2}{|r|}{ Brasil } & \multicolumn{2}{|c|}{ Paraná } \\
\hline & 2005 & 2015 & 2005 & 2015 \\
\hline $\begin{array}{l}\text { Explicada total } \\
\sum_{j} \beta_{j}^{L}\left(\bar{X}_{j}^{H}-\bar{X}_{j}^{L}\right)\end{array}$ & $-17,90 *$ & $-17,40^{*}$ & $-15,21^{*}$ & $-13,60 *$ \\
\hline Educação & $-11,43^{*}$ & $-8,38 *$ & $-11,48 *$ & $-5,68 *$ \\
\hline $\begin{array}{l}\text { Discriminação de gênero } \\
\left(\beta_{0}^{\mathrm{H}}-\beta_{0}^{\mathrm{L}}\right)+\sum_{j} \bar{X}_{j}^{\mathrm{L}}\left(\beta_{\mathrm{j}}^{\mathrm{H}}-\beta_{\mathrm{j}}^{\mathrm{L}}\right)\end{array}$ & $31,39^{*}$ & $29,16^{*}$ & $32,20 *$ & $31,76^{*}$ \\
\hline $\begin{array}{l}\text { Diferença total } \\
\left(\overline{\mathrm{Y}}^{\mathrm{H}}-\overline{\mathrm{Y}}^{\mathrm{L}}\right)\end{array}$ & $7,88^{*}$ & $6,69^{*}$ & $12,10^{*}$ & $13,85^{*}$ \\
\hline
\end{tabular}

Fonte: Elaboração própria com base nos dados da PNAD 2005 e 2015.

Nota: $(*)$ significância a 5\%.

Do ponto de vista da diferença salarial de gênero e o papel da educação no país, os resultados deste trabalho foram consistentes com os encontrados na literatura nos anos pós 2000. No entanto, esta pesquisa aprofunda os desfechos para o Paraná, confirmando a importância da educação como fonte das desigualdades de gênero, com relativa perda de significado no ano mais recente.

\section{CONCLUSÃO}

O principal objetivo deste trabalho foi mensurar e analisar o impacto da educação no diferencial de salários entre mulheres e homens no estado do Paraná nos anos de 2005 e 2015.

Os ocupados paranaenses eram majoritariamente masculinos, brancos, pertenciam ao mercado de trabalho formal e moravam em região urbana para os dois anos analisados. Os resultados do Paraná confirmam a vantagem salarial a favor dos homens que vai ao encontro da literatura brasileira, particularmente em decorrência da maior experiência masculina e maior valorização da hora trabalhada dos homens, apesar dos maiores níveis de escolaridade femininos.

A educação e experiência apresentaram retornos positivos sobre os salários horas dos trabalhadores (de acordo com a teoria do capital humano), entretanto, os respectivos retornos no caso dos homens foram superiores aos das mulheres. Além disso, o impacto percentual de um ano adicional de estudo foi maior que o ganho percentual de um ano adicional de experiência tanto no 


\section{FAZ CIÊNCIA, VOL. 23, N. 38, JUL/DEZ DE 2021 - P. 96 - 117}

âmbito estadual para homens e mulheres como na análise nacional, porém estes retornos sofreram queda para os dois gêneros entre os dois anos estudados.

A decomposição salarial confirmou que, nos dois anos analisados, os salários masculinos do Paraná foram superiores aos femininos, e diferentemente do que aconteceu no Brasil como um todo, o hiato salarial entre homens e mulheres do estado elevou-se. Quando decompostas as diferenças salariais entre os gêneros no Paraná, constatou-se que o fator discriminante se reduziu, enquanto as diferenças explicadas pelas características dos trabalhadores, a despeito do efeito positivo para as mulheres trabalhadoras, foram menores no ano de 2015. Especificamente, o fator discriminante é relativamente mais expressivo e provocador das desigualdades de gênero, mas a educação é a causa mais importante das diferenças salariais na perspectiva dos fatores produtivos e dos postos de trabalho, que favorece a mulher trabalhadora, muito embora esse legado positivo tenha sido reduzido no período em análise.

Considerando-se que a literatura sobre as causas das diferenças salariais de gênero no estado ainda seja bastante incipiente, os resultados expostos nesta pesquisa, podem servir para informar de forma criteriosa e auxiliar como instrumento para a elaboração de ações públicas ou privadas que visem alavancar o acesso à educação, tendo em vista principalmente que a educação é um fator que favorece os rendimentos da mulher, e mitigar as fontes discriminatórias femininas.

\section{REFERENCIAS}

ARAÚJO, V. F.; RIBEIRO, E. P. Diferenciais de salários por gênero no Brasil: uma análise regional. 2000. Dissertação (Mestrado em Economia)-Universidade Federal do Rio Grande do Sul, Porto Alegre, 2000.

BATISTA, N. N. F.; CACCIAMALI, M. C. Diferencial de salários entre homens e mulheres segundo a condição de migração. Revista Brasileira de Estudos da População, Rio de Janeiro, v. 26, n. 1, p. 97-115, jan./jun. 2009.

BERNI, H. A.; BARRETO, F. A.; SIQUEIRA, M. L. Determinantes recentes da desigualdade salarial no Nordeste do Brasil. Fortaleza: Laboratório de Estudos da Pobreza-UFC, 2007.

BLINDER, A. S. Wage discrimination: reduced form and structural estimates. The Journal of Human Resources, v. 8, n. 4. Aug, 1973.

BRANCHI, B. A.; FIGUEIREDO, N. M. S. Diferenças de rendimentos entre homens e mulheres no rural brasileiro em 2010. In: ENCONTRO NACIONAL DA ABET, 13., 2013, Curitiba. Anais... Curitiba: UFPR, 2013. 


\section{FAZ CIÊNCIA, VOL. 23, N. 38, JUL/DEZ DE 2021 - P. 96 - 117}

CACCIAMALI, M. C.; HIRATA, G. I. Discriminação ou grupos em situação de desvantagem no mercado de trabalho? Uma análise do mercado de trabalho brasileiro acerca da raça e gênero. Revista de Economia Mundial, Huelva, v. 12, p. 53-86, 2005.

CASARI, P. Segmentação no mercado de trabalho brasileiro: diferenças entre o setor agropecuário e os setores não agropecuários, período de 2004 a 2009. 2012. Tese (Doutorado em Economia Aplicada)-Universidade de São Paulo, Piracicaba, 2012.

CATELAN, D. W. Uma abordagem das diferenças salariais e da discriminação por gênero e cor no mercado de trabalho da região Sul do Brasil, em 2002 e 2013. 2016. Monografia (Curso de Ciências Econômicas) - Centro de Estudos Sociais Aplicados, Universidade Estadual de Londrina, Londrina, 2016.

CAVALIERI, C. H.; FERNANDES, R. Diferenciais de salários por gênero e cor: uma comparação entre as regiões metropolitanas brasileiras. Revista de Economia Política, v. 18, n. 1 (69), p. 158-175, jan./mar. 1998.

CHAVES, A. L. L. Estimativa da discriminação salarial, por gênero, para os trabalhadores assalariados da região metropolitana de Porto Alegre. Mulher e Trabalho, Porto Alegre, v. 2, p. 85-94, 2002.

MAIA, K.; DEVIDÉ JUNIOR, A.; SOUZA, S.C.I.; CUGINI, S.C.B. A mão de obra feminina no mercado de trabalho brasileiro: discriminação salarial por gênero. Ciências Sociais em Perspectiva, v.14, n.26, p. 30 - 53, 2015.

FIUZA-MOURA, F. K.; SOUZA, S. C. I.; MAIA, K. Capital humano e segmentação no mercado de trabalho: uma análise da indústria catarinense, por níveis de intensidade tecnológica. In: ENCONTRO DE ECONOMIA CATARINENSE, 8., 2014, Rio do Sul. Anais... Rio do Sul: APEC, 2014.

GOMES, M. R. Discriminação salarial de gênero e alocação por setor econômico dos trabalhadores no Primeiro emprego, Reemprego e Remanescentes: regiões Sul e Nordeste do Brasil. Dissertação (Mestrado em Economia Regional) - Centro de Estudos Sociais Aplicados, Universidade Estadual de Londrina, Londrina, 2016. 


\section{FAZ CIÊNCIA, VOL. 23, N. 38, JUL/DEZ DE 2021 - P. 96 - 117}

IBGE. INSTITUTO BRASILEIRO DE GEOGRAFIA E ESTATÍSTICA. Pesquisa Nacional por Amostra de Domicílios, 2005. Rio de Janeiro, 2006. Disponível em:

<http://www.ibge.gov.br/home/estatistica/populacao/trabalhoerendimento/pnad2014/microdados .shtm>. Acesso em: 14 out. 2016.

IBGE. INSTITUTO BRASILEIRO DE GEOGRAFIA E ESTATÍSTICA. Pesquisa Nacional por Amostra de Domicílios, 2015. Rio de Janeiro, 2016. Disponível em:

<http://www.ibge.gov.br/home/estatistica/populacao/trabalhoerendimento/pnad2015/microdados

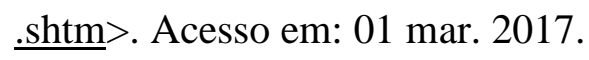

JACINTO, P. A. Diferenciais de salários por gênero na indústria avícola da região Sul do Brasil: uma análise com micro dados. Revista de Economia e Sociologia Rural, Rio de Janeiro, v. 43, n. 3, p. 529-555, jul./set. 2005.

MALDANER, I. S. Discriminação por gênero no mercado de trabalho paranaense. 2004. Trabalho de Conclusão de Curso (Graduação em Ciências Econômicas)-Universidade Estadual do Oeste do Paraná, Toledo, 2004.

MATTEI, T. F.; BAÇO, F. M. B. Análise da existência de discriminação salarial entre gêneros na indústria de transformação do estado de Santa Catarina. In: ENCONTRO DE ECONOMIA CATARINENSE, 9., 2015, Chapecó. Anais... Chapecó: APEC, 2015.

MENEZES-FILHO, N. A. A evolução da educação no Brasil e seu impacto no mercado de trabalho. São Paulo: Instituto Futuro Brasil, 2001.

MORAES, S. M. A. Discriminação salarial por gênero nos segmentos industriais do Brasil: uma análise para os anos de 1993, 1998 e 2003. 2005. (Mestrado em Desenvolvimento Econômico)-Universidade Federal do Paraná, Curitiba, 2005.

NERI, I. L. A.; ARAÚJO, I.T.; FIGUEIREDO, N.R.M.; SANTOS, J.M. Decomposição do diferencial regional de salário entre gêneros: uma abordagem por regressões quantílicas. In: FÓRUM BNB DE DESENVOLVIMENTO, 2009, Fortaleza. Anais... Fortaleza: BNB, 2009. 


\section{FAZ CIÊNCIA, VOL. 23, N. 38, JUL/DEZ DE 2021 - P. 96 - 117}

NOGUEIRA, J.; MARINHO, E. Discriminação salarial por raça e gênero no mercado de trabalho das regiões nordeste e sudeste. In: ENCONTRO NACIONAL DE ECONOMIA, 34. , 2006, Salvador. Anais... Salvador: ANPEC, 2006.

OAXACA, R. Male-Female wage differentials in urban labor markets. International Economic Review, v. 14, n. 3. Oct. 1973.

OLIVEIRA, K. C.; HEREK, M. Mulher no mercado de trabalho: um levantamento sobre as diferenças salariais entre gêneros na microrregião de Paranavaí e no estado do PR. In: SEMINÁRIO DO TRABALHO, 9., 2014, Marília. Anais... Marília: UNESP, 2014.

PEREIRA, R. M.; OLIVEIRA, C. A. Os diferenciais de salário por gênero no Rio Grande do Sul: uma aplicação do modelo de heckman e da decomposição de Oaxaca-Blinder. Redes, v. 21, no 1, p. 148 - 173, jan./abr. 2016.

SILVA, V. H. M. C.; FRANÇA, J. M. S.; PINHO NETO, V. R. Capital humano e desigualdade salarial no Brasil: uma análise de decomposição para o período 2001-2012. In: FÓRUM DE COMUNICAÇÃO DO GOVERNO FEDERAL NO NORDESTE, 5., 2014, Fortaleza. Anais... Fortaleza: BNB, 2014.

SOARES, S. Discriminação de gênero e de raça no mercado de trabalho. Mercado de trabalho: Conjuntura e Análise, n. 13, p. 45-51, jun. 2000.

SOARES, R. R.; GONZAGA, G. Determinação de salários no Brasil: dualidade ou não linearidade no retorno à educação? Rio de Janeiro: PUC-RIO, 1997.

SULIANO, D.C.; SIQUEIRA, M. L. Um estudo do retorno da educação na região nordeste: análise dos estados da Bahia, Ceará e Pernambuco a partir da recente queda da desigualdade. Fortaleza: IPECE, 2009. 22 p.

TAVARES, P. A.; MENEZES-FILHO, N. A. O papel do capital humano na desigualdade de salários no Brasil entre 1981 e 2006. In: ENCONTRO NACIONAL DE ESTUDOS POPULACIONAIS, 16., 2008, Caxambú. Anais... Caxambú: ABEP, 2008. 